\title{
Pathology of Intracardiac Nerves in Experimental Chagas Disease
}

\author{
Lídia Cristina Villela Ribeiro, Aryon A Barbosa Jr., Zilton A Andrade
}

\author{
Laboratório de Patologia Experimental, Centro de Pesquisas Gonçalo Moniz- Fiocruz, Rua Valdemar Falcão 121, \\ 40295-001 Salvador, BA, Brasil
}

Severe destruction of intrinsic cardiac nerves has been reported in experimental acute Chagas myocarditis, followed by extensive regeneration during the chronic phase of the infection. To further study this subject, the sympathetic and para-sympathetic intracardiac nerves of mice infected with a virulent Trypanosoma cruzi strain were analyzed, during acute and chronic infection, by means of histological, histochemical, morphometric and electron microscopic techniques. No evidences of destructive changes were apparent. Histochemical demonstration for acetylcholinesterase and catecholamines did not reveal differences in the amount and distribution of intracardiac nerves, in mice with acute and chronic Chagas myocarditis or in non-infected controls. Mild, probably reversible ultrastructural neural changes were occasionally present, especially during acute myocarditis. Intrinsic nerves appeared as the least involved cardiac structure during the course of experimental Chagas disease in mice.

Key words: intracardiac nerves -Trypanosoma cruzi - Chagas disease - myocarditis

The demonstration that endemic megaesophagus and megacolon, found in areas of Chagas disease represented a digestive form of this disease raised considerable interest to the study of autonomic nervous system disturbances. Damage to nervous ganglia situated along the submucosa and muscular coats of the digestive tract was considered to lead to disperistalsis, which culminated in the development of megaesophagus and/or megacolon (Koberle 1961, Rezende 1984). Similar nervous changes also occurred in the heart. As a matter of fact, electrocardiographic alterations, associated with atrophy and fibrosis of cardiac nervous ganglia, were described in Brazilian cases of megaesophagus long before its relationship to Chagas disease was established (Oria \& Ramos 1949). Marked decrease in the number of cardiac ganglionic neurons has been registered in patients with Trypanosoma cruzi infection, when compared to normal controls (Koberle 1959) or to other forms of cardiopathies (Amorim \& Olsen 1982).

The impact of these findings has been so great as to lead some authors to suggest new terms such as "neurogenic cardiopathy" (Koberle 1959), "cardio-neuromyopathy" (Iosa et al. 1989) and "catecholamino-genic cardiopathy" (Oliveira 1985) for Chagas heart disease.

Additionally, patients with chronic T. cruzi infection were found to exhibit peripheral electromyographic changes, probably due to myo-neural involvement (Faria et al. 1979). An apparent support for the chagasic etiology of such findings came from the description of inflammatory and demyelinating neural changes observed in experimental Chagas disease (Barreira et al. 1981, Said et al. 1985).

$\overline{{ }^{+} \text {Corresponding author. Fax }}$ +55-71-356.2155. E-mail: zilton@cpqgm.fiocruz.br

Received 22 February 2002

Accepted 22 July 2002
However, much less attention has been paid to the lesions affecting the intrinsic nerves of the heart in Chagas disease. So far, only one group of investigators have devoted a series of papers to this subject (Machado et al. 1975, 1978, 1979, 1987, 1998). These papers, mainly based on histological findings, described severe, diffuse and focal, destructive cardiac neural lesions affecting both the sympathetic and parasympathetic fibers of the heart, during acute Chagas myocarditis in rats and dogs. Later on, when the infection entered its chronic phase, occurred extensive neural regeneration. Apparently, no attempts by others have been made to reproduce these impressive and important findings, probably because there are no clinical evidences during the course of Chagas heart disease to correlate with them. However, the data are present in the literature and need to be confirmed.

The present investigation is concerned with the description and interpretation of the lesions affecting the sympathetic and parasympathetic nerves of the heart, during acute and chronic experimental Chagas disease in mice, by means of histologic, histochemical, ultrastructural and morphometric methods.

\section{MATERIALS AND METHODS}

Outbred Albino Swiss mice of both sexes, weighing 16-18 g, maintained on a commercial balanced diet and water ad libitum, were used. Thirty animals were intraperitoneally inoculated with 50,000 trypomastigotes of the 21SF T. cruzi strain (Andrade \& Magalhães 1997), a cardiotropic strain. Parasitemia was registered daily from the 7 th up to the 20th day after inoculation, and once every week afterwards. Fifteen animals were not submitted to infection and served as normal controls. So, three groups of animals were considered for morphologic studies. 1st Group - Representative of the acute phase of the infection, 15 mice were sacrificed around the 20th day of infection, when parasitemia reached its highest peak. 2nd Group - Another 15 infected mice, representative of the chronic phase of the infection, were sacrificed 7 months after inoculation. 3rd Group - Normal control mice were maintained under the same general conditions of the other 
groups, and killed either on day 20 and on the 7th month after the beginning of the experiment. Animals from all groups were always killed under general ether anesthesia, followed by severing of the brachial plexus and exsanguination. The heart was removed, sectioned into two halves, along the great axis, through the inter-ventricular septum, and then immediately submitted to the several procedures as described below.

Histology - Portions of the heart were fixed in $10 \%$ phosphate buffered ( $\mathrm{pH}$ 7.2) formalin, embedded in paraffin, and the $5 \mu \mathrm{m}$-thick sections obtained were stained with hematoxylin and eosin ( $\mathrm{H} \& \mathrm{E})$.

Histochemistry - Half of the heart was embedded in Tissue-Tek (Sakura Finetek, Torrance, CA, USA) and quickly frozen in liquid nitrogen $\left(-196^{\circ} \mathrm{C}\right)$. The frozen blocks were placed in air-tight plastic boxes and kept in a freezer at $-80^{\circ} \mathrm{C}$ until the moment they were cut in a cryostat at $-20^{\circ} \mathrm{C}$. Sections, either floating or mounted on glass slides, were submitted to histochemical staining for the demonstration of acetyl-cholinesterase by a thiocholine method (Karnovsky \& Roots 1964), following fixation in formol-calcium for $10 \mathrm{~min}$. Slides were lightly counterstained by hematoxylin. Other sections were submitted to a glyoxylic acid-induced fluorescent method for the demonstration of catecholamines by the method of De la Torre (1980), as later modified by Cottle et al. (1985). For that, the sections mounted in mineral oil were examined under ultra-violet light in a Zeiss microscope with mercury lamp and appropriate exciter and barrier filters.

Electron microscopy - Tiny fragments taken from the right atrium of the heart were immediately fixed in $3 \%$ glutaraldehyde in $0.2 \mathrm{M}$ cacodylate buffer, post-fixed in $1 \%$ osmium tetroxide and embedded in epon resin. Selected blocks were cut in a Reichert Ultracut automatic ultramicrotome, with diamond knife, and the ultra-thin sections obtained were contrasted with uranyl acetate and lead citrate. Specimens were examined in a Zeiss EM-109 electron microscope, which was operated at an acceleration voltage of $80 \mathrm{kV}$.

Morphometry - Sections stained with H \& E and for acetyl-cholinesterase activity were analyzed by morphometry to quantitatively evaluate inflammation (by counting the number of leukocyte nuclei) and para-sympathetic nerves (by measuring the sectional area occupied by cholinesterase-positive fibers). The sections were examined by semi-automatic morphometry using the Leica Q500MC Image Processing and Analysis System (Leica, Cambridge, England). For morphometric measurements of nuclei, a total sectional area of $268,609 \mu \mathrm{m}^{2}$, with an objective of 10X, was considered; for cholinesterase-positive nerves the objective was $20 \mathrm{X}$ and the area examined was $65,104 \mu \mathrm{m}^{2}$.

Statistical analysis - Average numbers obtained by morphometry were compared by the Mann Whitney test, with the Graphpad Instat software. A significance level of $5 \%(\mathrm{p}<0.05)$ was accepted.

\section{RESULTS}

Normal mice - Segments of myelinated and nonmyelinated nerves were frequently observed in sections taken from the atrial walls of the heart and, rarely, the ventricles, always accompanied by arterial and venous blood vessels and capillaries. Acetyl-cholinesterase staining disclosed a rich network of fibers in the atrium, deeply marked by a strong dark brown color. A similar picture of a rather straight, delicate but less compact network of fluorescent fibers appeared when the histochemical method for catecholamines was applied. The nervous ganglia were frequently observed, especially in the sub-pericardial connective tissue of the right atrium. These structures, particularly the neurons, stained strongly positive for acetyl-cholinesterase.

Acute Chagas myocarditis - The myocardium appeared severely involved by mononuclear leukocyte infiltration, edema and congestion. Collections of $T$. cruzi amastigotes appeared here and there within myocardiocytes (Fig. 1A, arrow). Some nerves were seen in areas of dense infiltration by inflammatory cells. Although a few of these cells were seen at the periphery or within nervous ganglia, and a few neurons exhibited severe regressive changes, no alterations were observed within the structures of the intrinsic cardiac nerves on routine histological sections (Fig. $1 \mathrm{~A}, \mathrm{~B}$ ) or after histochemical staining for cholinesterase or catecholamines (Fig. 1 C, D, E, F). Sometimes inflammatory cells appeared to be invading nerve fibers, but the possibility of cells and fibers being at different planes of section could not be ruled out in the relatively thick routine histological sections examined. At the ultrastructural level no cell adhesion to the neural external membrane and no cell invasion of nerves were ever observed. Lymphocytes and macrophages were sometimes found adherent to or within destroyed myocardiocytes. In these instances there were swelling and rupture of mitochondria, myofibril aggregation, fragmentation and lysis of myocardiocytes.

Segments of myelinated and non-myelinated nerves were found in areas free of alterations or in close proximity to inflammatory changes. No signs of destructive changes were ever found, even after exhaustive search. Although the changes affecting the neural structures were mild and non-specific, they are registered in Figs 2 and 3 for the sake of documentation. They consisted of: (a) axoplasma abnormalities, such as increased number of membranous organelles, tumefaction and cristolysis of mitochondria, focal disintegration of neurotubules and neurofilaments, alterations of the myelin sheet, with increasing periodicity of lamellae, sometimes with myelin fragments appearing within the axoplasma or exhibiting several degrees of deformities; (b) alterations of Schwann cells, which frequently contained phagosomes of variable sizes, sometimes forming "myelin figures". In one instance a cytoplasmic prolongation of a Schwann cell appeared between the axolema and the myelin sheet. The terminal portions of non-myelinated nerve fibers exhibited preserved synaptic vesicles and a few dense bodies, besides mild mitochondrial non-specific alterations (Fig. $3 \mathrm{C})$.

A quantitative estimation of the severity of inflammatory changes and of the areas occupied by cholinesterase-positive nerves in cardiac sections, taken from mice with acute and chronic infections, as well as from normal controls, is depicted in the Table. 
Chronic Chagas myocarditis - Inflammatory changes were focal and mild in all cases. They consisting of scattered, small, focal accumulations of lymphocytes, plasmocytes and macrophages, located in the interstitial tissue of the heart, especially at the sub-pericardial areas of both atria (Fig. 1 B). Segment of nerves were seen within inflammatory foci, without any apparent structural alteration. This is true for the slides examined with $\mathrm{H} \& \mathrm{E}$ staining or treated with the histochemical methods for acethyl-cholinesterase and catecholamines. Changes ob-
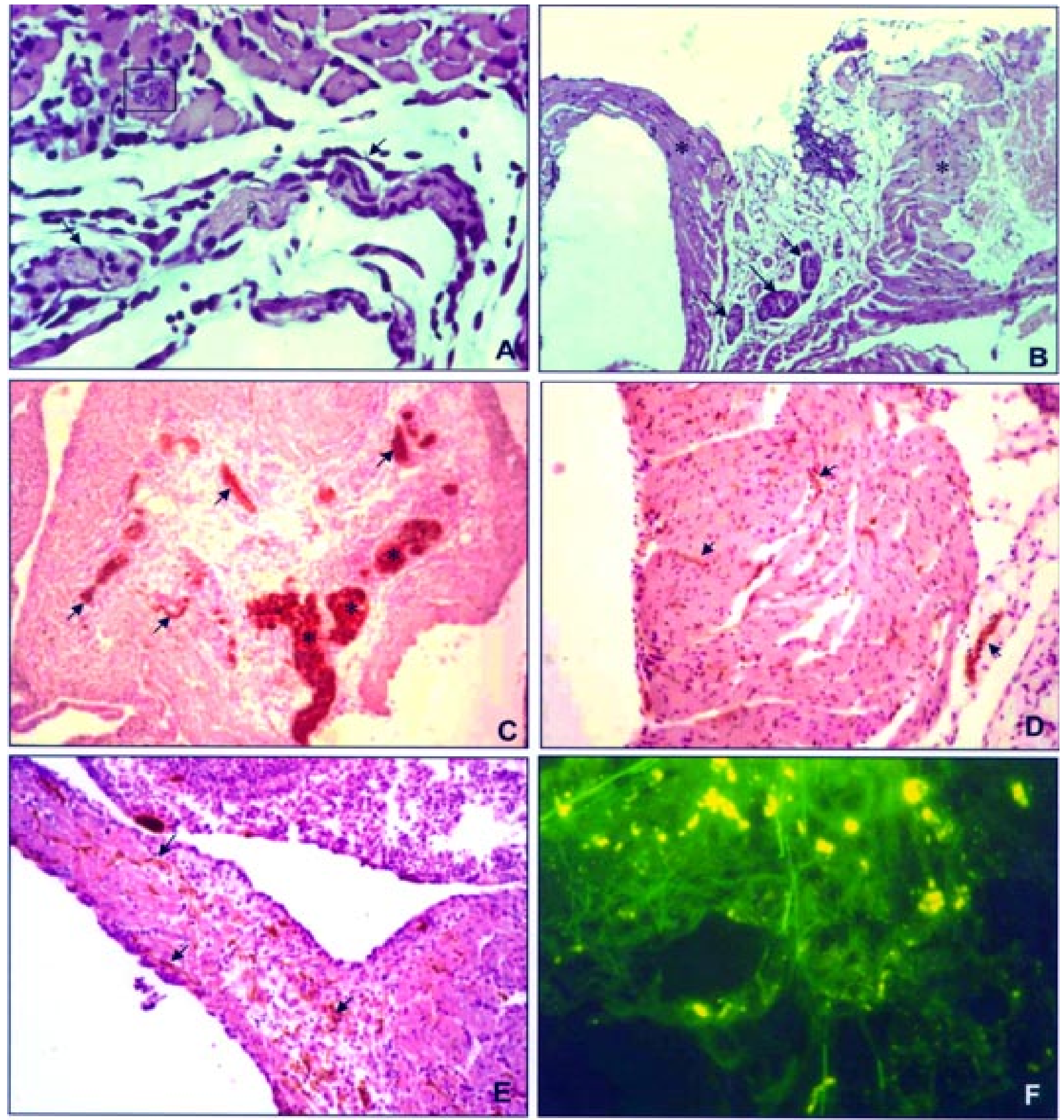

Fig. 1 A: acute Trypanosoma cruzi myocarditis in a mouse. There are intracellular amastigotes (arrow) and inflammatory cells in close proximity to preserved nerves (arrow head), Hematoxylin \& Eosin (H\&E), X 200; B: chronic Chagas myocarditis in a mouse, showing focal and dense mononuclear infiltration in ventricular connective tissue in the proximity of nerves (arrow head). The para-sympathetic nervous ganglia (arrows) and the myocardium appear preserved. H\&E, X 150; C: acetyl-cholinesterase activity appears strongly positive in parasympathetic ganglia (asteriscs) and nerves (arrow heads) in right atrial wall of a mouse with acute Chagas myocarditis. Karnovsky \& Root's method. X 150; D, E: demonstrate the presence of delicate cholesterinase-positive nerve fibers (arrow heads) in the atrial region of the heart during acute Chagas myocarditis. Karnovsky \& Root's method. X 250 (D), X150 (E); F: rich fluorescence due to catecholamine-containing nervous fibers (arrows) belonging to the sympathetic autonomic cardiac nervous system. Acute $T$. cruzi infection of mouse. Cryostat section submitted to a glyoxylic-acid method. X 200. 

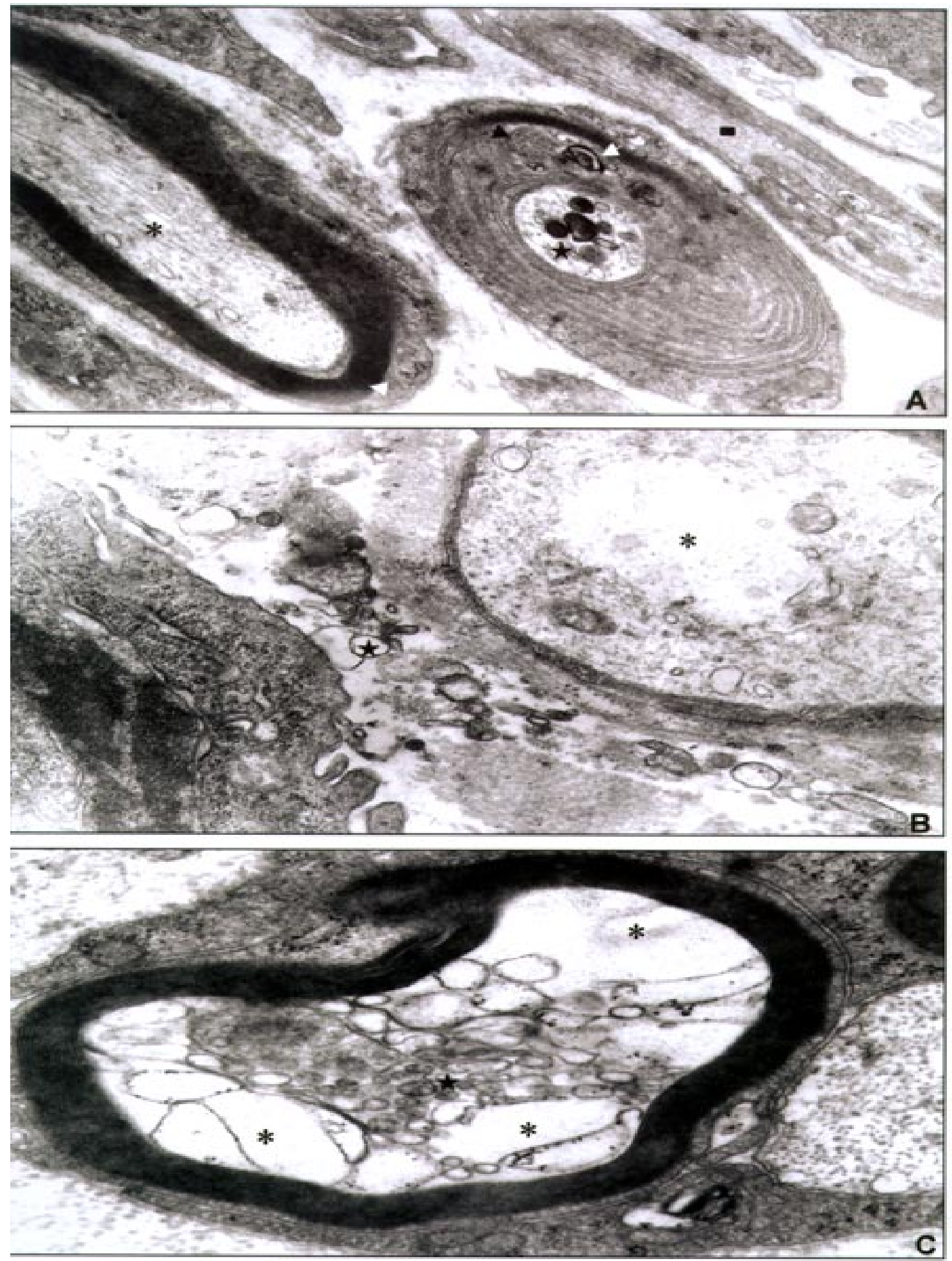

Fig. 2 A: murine acute Chagas myocarditis. Nerve fibers of the heart: in the middle, a fiber exhibiting unusually large myelin periodicity and accumulation of organelles within the axoplasm. The Schwann's cell reveals myelin figure and a multivesicular body (arrows). At upper right, there is a nonmyelinated fiber without alterations in axonal cytoskeletal proteins. At left a myelinated fiber shows preservation of both myelin (white arrow head) and axoplasm (asterisk). Electron micrograph, X 35,000; B: nonmyelinated nerve fiber situated in atrial cardiac tissue during acute T. cruzi infection showing cytoskeletal protein disintegration of the axoplasm (asterisk). Note cellular remains within the interstitial tissue. Electron micrograph, X 27,000; C: axonal microtubule and neurofilament disintegration (asterisks) are seen in a myelinated nerve fiber, which also reveals at the center many vesicles with variable density Electron micrograph, X 45,000. 

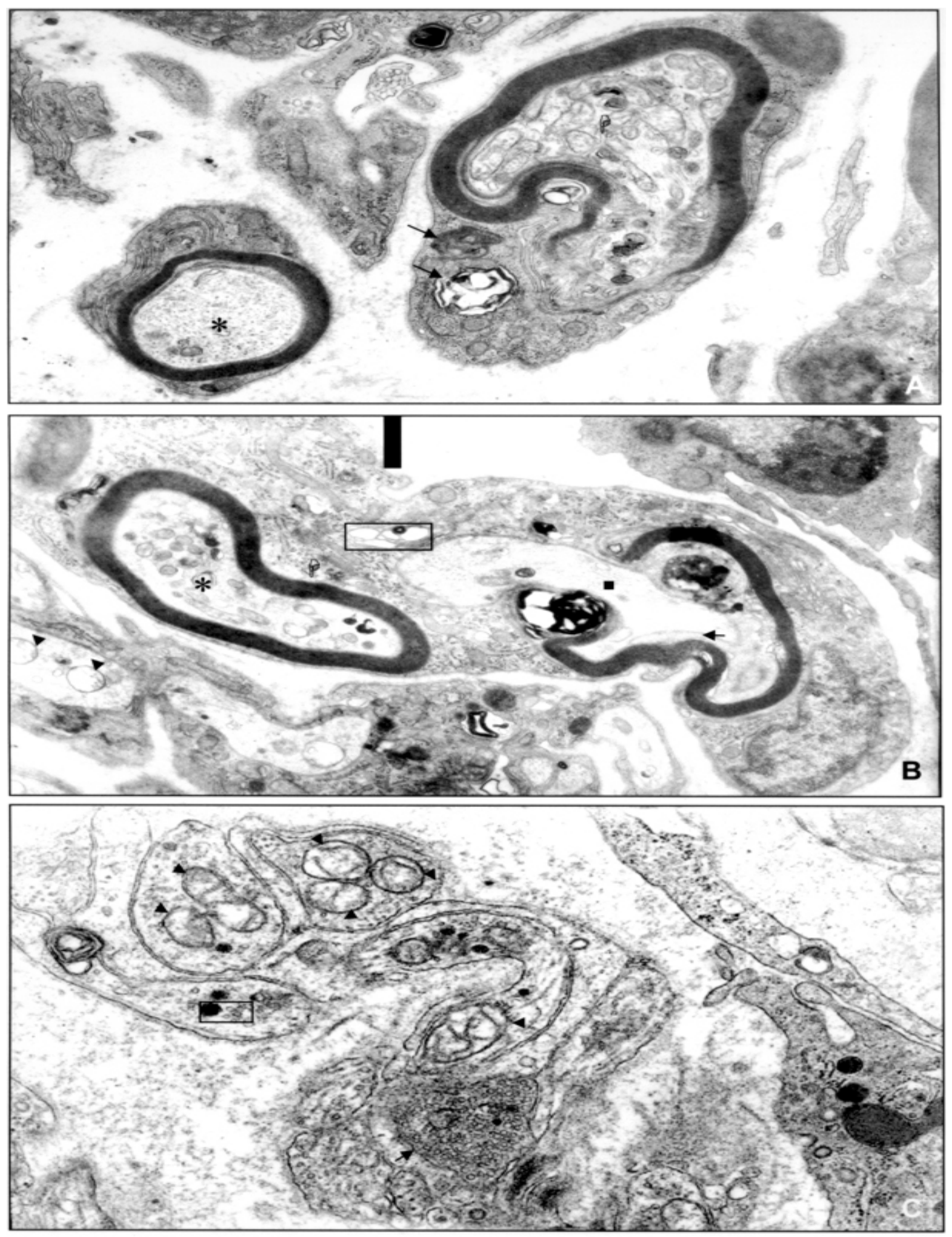

Fig. 3: myelinated nervous fibers of the heart showing accumulation of organelles within the axoplasma. A: Schwann cell presenting two phago-lysosomes (arrows). X 24, 500; B: the cytoplasm of Schwann cell penetrates between the paranodal myelin and the axolem (arrow). A Golgi apparatus exhibits vesicle dilatation (rectangle) and a myelinated fiber containing secretory vesicles of variable densities (asterisk). There are some nonmyelinated fibers with axoplasmic dilated mitochondria (arrow heads). Electron micrograph, X 22,000; C: terminal non-myelinated nerves situated in atrial cardiac tissue during acute $T$. cruzi infection showing a preserved synaptic vesicle, with mild intestitial edema, mild non-specific mitochondrial alterations (arrows) and a few dense bodies (arrows). Electron micrograph, X 27,000. 
TABLE

Morphometric estimation of the number of nuclei, reflecting intensity of inflammation, in sections from the right cardiac atrium (1st column), and the percentage of a given sectional area occupied by nerve fibers as seen in sections of the atrium stained for acethyl-cholinesterase activity in acute and chronic

Chagas myocarditis as compared to normal controls ( 2 nd column)

\begin{tabular}{lcc}
\hline Groups & $\begin{array}{c}\text { Cell-nucleus } \\
\overline{\mathrm{X}} \pm \mathrm{SD}\end{array}$ & $\begin{array}{c}\text { Nerve fibers } \\
\overline{\mathrm{X}} \pm \mathrm{SD}\end{array}$ \\
\hline $\begin{array}{l}\text { 1st Group } \\
\text { (Acute Infection) }\end{array}$ & $483 \pm 213$ & $6.0 \pm 4.4$ \\
$\begin{array}{l}\text { 2nd Group } \\
\text { (Chronic Infection) }\end{array}$ & $287 \pm 112$ & $9.0 \pm 6.2$ \\
Normal control & $142 \pm 70$ & $6.2 \pm 4.2$ \\
\hline
\end{tabular}

Differences for any two Groups in the first column (Cell-nuclei) were statistically significant, but no significance occurred between any two Groups of the second column (Nerve fibers).

served by electron microscopy in the myelinated and non-myelinated myocardial nerves were qualitatively similar to those seen during the acute phase myocarditis, but less intense and less frequent. No evidences of axonal regenerative sprouts were observed during either the acute or chronic phase of the infection.

\section{DISCUSSION}

Present investigation demonstrated relatively mild, reversible and non-specific ultrastructural changes affecting the intracardiac nerves during the course of experimental Chagas disease in the mouse. Such changes are probably secondary to neighboring inflammation, since they appeared more evident when associated with severe acute myocarditis of early $T$. cruzi infection, than with chronic infection, when myocarditis became mild and focal. On the other hand, signs of lymphoid and/or macrophagic cytoadherence and cytotoxicity, although noted in myocardiocytes during acute myocarditis, were not observed in nerves. The possibility of disappearance or even the occurrence of partial destruction of intracardiac nerves could not be demonstrated, neither by morphometric means in sections histochemically prepared for parasympathetic nerves, nor by electron microscopy. Therefore, present data are in marked contrast with the reported findings of severe destruction of nerves followed by extensive regeneration observed in rats (Machado et al. 1979, 1987) and dogs (Machado et al. 1998) with $T$. cruzi infection. Actually, the Machado's group demonstrated neither destruction, nor regeneration of cardiac nerves, but disappearance and re-appearance of enzymatic reactivity in acute and chronic Chagas myocarditis, respectively, in rats and dogs. The particularly severe myocarditis, occurring in rats and dogs, much more intense than that obtained with the present experiments in mice, may be accounted for such observed differences in enzymatic reactivity. However, it is worth mentioning that in dogs with severe acute Chagas myocarditis, ultrastruc- tural findings on cardiac nerves consisted only of swelling of Schwann cells and increased sizes and numbers of dark granules and vesicles (Andrade et al. 1994).

Of course the present study does not rule out the possibility that a certain amount of neural destruction occurs during the course of acute Chagas myocarditis. Neuronal loss may occur in the atrial parasympathetic ganglia, although a mild focal nature, as observed during severe acute myocarditis of mice (Souza et al. 1996), when three different $T$. cruzi strains were compared. When a neuron is destroyed, the associated axon undergoes Wallerian degeneration. Although the ultrastructural changes observed in the present study were mild, they are qualitatively similar to those observed during early Wallerian degeneration (Vial 1958, Donat \& Wisniewski 1973). These non-specific changes are also common during inflammation, when a modification of the permeability of the nerve membrane can result in edema, due to an augmented influx of ions. According to Schlaepfer (1974) and Schlaepfer and Hasler (1979), an intra-axonal increase in calcium concentration results in a granular aspect of the axoplasm, with disintegration of microtubules and microfilaments. This process is probably mediated by a calcium-activated neutral protease (Kamakura et al.1983).

In conclusion, despite the presence of the non-specific neural changes observed in the present material, the intrinsic nerves of the heart appeared as one of the structures least involved during the course of acute and chronic Chagas myocarditis.

\section{REFERENCES}

Amorim DS, Olsen ECJ 1982. Assessement of heart neurons in dilated (congestive) cardiomyopathy. Brit Heart $J$ 47: 11-18.

Andrade SG, Magalhães JB 1997. Biodemes and zymodemes of Trypanosoma cruzi strains: correlations with clinical data and experimental pathology. Rev Soc Bras Med Trop 30: 27-35.

Andrade ZA, Andrade SG, Correa R, Sadigursky M, Ferrans VJ 1994. Myocardial changes in acute Trypanosoma cruzi infection. Ultrastructural evidence of immune damage and the role of microangiopathy. Am J Pathol 144: 1403-1411.

Barreira AA, Saide G, Krettli AU 1981. Multifocal demyeliniative lesions of peripheral nerves in experimental chronic Chagas' disease. Trans R Soc Trop Med Hyg 75: 751.

Cottle MKW, Cottle WH, Pérusse F, Bukowiecki LJ 1985. An improved glyoxylic acid technique for the histochemical localization of catecholamines in brown adipose tissue. Histochem J 17: 1279-1288.

De la Torre JC 1980. An improved approach to histofluorescence using the SPG method for tissue monoamines. $J$ Neurosci Meth 3: 1-5.

Donat JR, Wisniewski HM 1973. The spatio-temporal pattern of Wallerian degeneration in mammalian nerves. Brain Res 53: 41-53.

Faria CRD, Melo-Souza SE, Rassi A, Lima AF 1979. Evidências eletromiográficas de desnervação motora em pacientes na fase aguda da doença de Chagas. Rev Goiana Med 25: 153-155.

Iosa DJ, DeQuatro V, Lee DD, Palmero H 1989. Plasma neuroepinephrine in Chagas' cardioneuromyopathy: a marker of progressive dysautonomia. Am Heart J 117: 882887. 
Kamakura K, Ushiura S, Sugita H, Toyokuura Y 1983. Identification of $\mathrm{Ca}^{2+}$ activated neutral protease in the peripheral nerves and its effects on neurofilament degeneration. $J$ Neurochem 40: 908-913.

Karnovsky MJ, Roots LA 1964. A direct-coloring thiocholine method for cholinesterase. J Histochem Cytochem 12: 219-221.

Koberle F 1959. Cardiopathy parasympaticopriva. München Med Wschr 101: 1202-1203.

Koberle F 1961. Patologia y anatomia patológica de la enfermedad de Chagas. Bol Ofic Sanit Panam 51: 404-428.

Machado ABM, Machado CRS, Gomes CB 1975. Depletion of heart norepinephrine in experimental acute myocarditis caused by Trypanosoma cruzi. Experimentia 31: 1202-1223.

Machado ABM, Machado CRS, Gomes CB 1979. Trypanosoma cruzi: acethylcholine content and cholinergic innervation of the heart in rats. Exp Parasitol 47: 107-115.

Machado CRS, Caliari MV, de Lana M, Tafuri WL 1998. Heart autonomic innervation during the acute phase of experimental American trypanosomiasis in the dog. Am J Trop Med Hyg 59: 492-496.

Machado CRS, Gomez MV, Machado ABM 1987. Changes in choline acethyltransferase activity of rat tissues during Chagas' disease. Braz J Med Biom Biol Res 20: 697-702.

Machado CRS, Machado ABM, Chiari CA 1978. Recovery from heart norepinephrine depletion in experimental Chagas' disease. Am J Trop Med Hyg 27: 20-24,

Oliveira JSM 1985. A natural human model of intrinsic heart nervous system denervation: Chagas cardiopathy. Am Heart J 110: 1092-1098.

Oria JS, Ramos J 1949. Alterações do metassimpático do coração nos portadores de megaesôfago (cardiospasmo). Arq Bras Cardiol 2: 311-326.

Rezende JM 1984. The digestive tract in Chagas' disease. Mem Inst Oswaldo Cruz 79: 97-106.

Said GM, Joskovicz AA, Barreira A, Eisen A 1985. Neuropathy associated with experimental Chagas' disease. Ann Neurol 18: 676-683.

Schlaepfer WW 1974. Calcium-induced degeneration of axoplasm in isolated segments of rat peripheral nerve. Brain Res 69: 203-215.

Schlaepfer WW, Hasler MB 1979. Characterization of the calcium-induced disruption of neurofilaments in rat peripheral nerve. Brain Res 168: 299-309.

Souza MM, Andrade SG, Barbosa Jr AA, Santos RTM, Alves VA, Andrade ZA 1996. Trypanosoma cruzi strains and autonomic nervous system pathology in experimental Chagas' disease. Mem Inst Oswaldo Cruz 91: 217-224.

Vial JD 1958. The early changes in the axoplasm during Wallerian degeneration. J Bioph Biochem Cytol 4: 551-556. 